\title{
The Effect of Two Different Types of Anesthesia on Postoperative Liver Functions in Metabolic Syndrome Patients with Coronary Bypass
}

Etik Kurul Onayı: Hastanemizin Etik Kurulu onayı alınmıştır (No: E-17-1692, 03.01.2018)

Çıkar Çatışması: Makalemizde çıkar çatışması bulunmamaktadır. Finansal Destek: Makalemizde finansal destek alınmamıștır. Hasta Onamı: Tüm hastalardan onam alınmışıır.
Ethics Committee Approval: The approval of our hospital's Ethics Committee was obtained (No: E-17-1692, 03.01.2018).

Conflict of Interest: There is no conflict of interest in our study.

Funding: Informed consent was obtained from participants included in the study. Informed Consent: Consent was obtained from all patients.

Cite as: Yiğit Özay H, Demir A, Kaya Bahçecitapar M. Metabolik sendromlu koroner baypas hastalarında uygulanan iki farklı anestezi tipinin postoperatif karaciğer fonksiyonları üzerine etkisi. GKDA Derg. 2021;27(1):30-7.

Öz

Amaç: Metabolik sendromlu (MS) hastaların koroner baypas cerrahisinde (KABG) karaciğer fonksiyonlarını etkileyen faktörlerden biri kullanılan anestezi ilaçları olabilir. Bu amaçla KABG geçirecek MS'lu hastalarda, midazolam bazlı total intravenöz anestezi(TiVA) ve sevofluran bazlı inhalasyon anestezi uygulamasının, karaciğer fonksiyonları ve postoperatif komplikasyonlar üzerine etkilerin araştırdık.

Yöntem: Çalışmamıza 76 hasta dâhil edildi. TiVA ( $n=38)$ ve SEVO (n=38) grupları arasında cinsiyet, yaş, vücut kitle indeksi (VKi), euroscore değerleri, ameliyat öncesi komorbidite varlığı, kan ürünü transfüzyonu, postoperatif komplikasyon ve 30 günlük mortalite oranları açısından istatistiksel olarak anlamlı bir fark yoktu ( $p>0.05)$. Preoperatif ve postoperatif laboratuvar parametrelerine göre karşılaştırıldığında her 2 grupta da ALT, AST, LDH ve glukoz değerleri benzer bulundu. Bulgular: Calıșamızda, metabolik sendromlu koroner baypas hastalarında midazolam bazlı TiVA ve sevofluran bazlı inhalasyon anestezi uygulamalarının birbirine üstünlüğü olmadığını saptadık. Daha fazla sayıda hasta ile detaylı parametrelerin araştıııldığı çalışmalar bu konu için yol gösterici olacaktır. Sonuç: Çalışmamızda, metabolik sendromlu koroner baypas hastalarında midazolam bazlı TivA ve sevofluran bazlı inhalasyon anestezi uygulamalarının birbirine üstünlüğü olmadığını saptadık. Daha fazla sayıda hasta ile detaylı parametrelerin araştırıldığı çalışmalar bu konu için yol gösterici olacaktır.

Anahtar kelimeler: metabolik sendrom, koroner baypas cerrahisi, sevofluran, midazolam, obezite

ABSTRACT

Objective: One of the factors affecting liver functions in open coronary surgery (CABG) of patients with metabolic syndrome (MS) may be the anesthetic drugs used. For this purpose, we investigated the effects of midazolam-based total intravenous anesthesia (TIVA) and sevoflurane-based inhalation anesthesia on liver functions and postoperative complications in patients with MS who wiould undergo open coronary bypass surgery.

Method: A total $f 76$ patients were included in our study. A statistically significant difference was not found between the TIVA $(n=38)$ and SEVO $(n=38)$ groups in terms of gender, age, body mass index (BMI), Euroscore values, presence of preoperative comorbidity, blood product transfusion, postoperative complications, and 30-day mortality rates. ( $p>0.05)$. Preoperative and postoperative laboratory parameters, ALT, AST, LDH, and glucose values were comparable between both groups. Results: 76 patients were included in our study. There was a statistically significant difference between the TIVA $(n=38)$ and SEVO $(n=38)$ groups in terms of gender, age, body mass index (BMI), euroscore values, presence of preoperative comorbidity, blood product transfusion, postoperative complications, and 30-day mortality rates. There was no difference $(p>0.05)$. When compared according to preoperative and postoperative laboratory parameters, ALT, AST, LDH, and glucose values were found similar in both groups.

Conclusion: In our study, we found that TIVA and SEVO groups are not superior to each other in coronary bypass patients with metabolic syndrome. Studies investigating detailed parameters with more patients will be guiding for this issue.

Keywords: metabolic syndrome, coronary bypass surgery, sevoflurane, midazolam, obesity
Received/Geliş: 18.09 .2020

Accepted/Kabul: 24.11.2020

Published Online/Online yayın: 23.03.2021

Hülya Yiğit Özay

Ankara Şehir Hastanesi

Anesteziyoloji ve Reanimasyon Kliniği

Ankara - Türkiye

yigitozay@hotmail.com ORCID: 0000-0002-4104-6924

A. Demir 0000-0003-3053-0443 Ankara Sehir Hastanesi Anesteziyoloji ve Reanimasyon Kliniği Ankara, Türkiye

M. K. Bahçecitapar 0000-0002-5443-6278 Hacettepe Üniversitesi istatistik Anabilim Dalı Ankara, Türkiye

(C) Telif hakkı Göğüs Kalp Damar Anestezi ve Yoğun Bakım Derneği'ne aittir. Logos Tıp Yayıncılık tarafindan yayınlanmaktadır. Bu dergide yayınlanan bütün makaleler Creative Commons Atff-Gayri Ticari 4.0 Uluslararası Lisansı ile lisanslanmıştır.

(c) Copyright The Society of Thoracic Cardio-Vascular Anaesthesia and Intensive Care. This journal published by Logos Medical Publishing. Licenced by Creative Commons Attribution-NonCommercial 4.0 International (CC BY) 
H. Yiğit Özay ve ark., Metabolik Sendromlu Koroner Baypas Hastalarında Uygulanan İki Farklı Anestezi Tipinin Postoperatif Karaciğer Fonksiyonları Üzerine Etkisi

\section{GiRiş}

Santral obezite, dislipidemi, hipertansiyon, diabetes mellitus gibi aterosklerotik risk faktörlerinin birkaçının bir arada bulunmasıyla tanımlanan metabolik sendrom (MS) için genetik veya çevresel nedenlerle gelişen insülin direnci ana etkendir. Bu zeminde gelişen risk faktörleri karaciğerde basit yağ asitlerinin birikimine (hepatosteatoz) ve transaminaz yüksekliğine neden olabilir ${ }^{[1-3]}$. MS toplumda \%20-30 oranında görülmektedir ve her geçen yıl bu oran artmaktadır. Ayrıca kardiyovasküler hastalık riskini 2 kat arttırdığı belirtilmektedir ${ }^{[6,7]}$. Kalp cerrahisine gelen hastaların ise \% 23-46 oranında MS olduğu bildirilmektedir $[1-7,8]$. Yapılan çalışmalarda, MS, KABG ameliyatı sonrası mortalite için bağımsız bir predispozan faktör gibi görünmektedir ${ }^{[9-3]}$.

Midazolam kontrollü hemodinamik değişiklikler sağlaması nedeniyle kardiyovasküler cerrahide uzun yıllardır güvenle kullanılan bir anestezik ilaçtır. Birçok ilaç gibi midazolam da esas olarak karaciğerde metabolize olur. CYP3A4 ve CYP3A5 tarafından hidroksilasyonla aktif metaboliti olan 1-OH midazolama dönüşür. Ardından glukronidasyona uğrar ve böbrekler yoluyla atılır ${ }^{[10]}$. Midazolamın bolus ya da infüzyon şeklinde kullanımına bağı ender olarak serum alanin aminotransferaz (ALT) yükselmeleri bildirilmiştir. Klinik olarak belirgin bir karaciğer hasarı gözlenmemiştir ${ }^{[11]}$. Ancak, MS'li hastalarda santral obezite, bozulmuş glukoz toleransı, karaciğer disfonksiyonu, sitokrom P450 (CYP) sistemleri gibi nedenlerle midazolamın metabolizması etkilenebilir. İnhalasyon anesteziklerinin miyokardial korumaya katkıda bulunduğu gösterildikten sonra kalp cerrahisinde volatil teknikler tercih edilir hâle gelmiştir ${ }^{[12]}$. Son yıllarda kardiyovasküler cerrahi anestezisinde daha sık kullanılan sevofluran ile hızlı derlenme ve kısa sürede ekstübasyon koşullarının sağlanması önemli avantajlar sağlamaktadır. Midazolamın aksine sevofluranın, kanda az miktarda çözünmesi, büyük oranda değişmeden akciğerden uzaklaştırılması nedeniyle karaciğer fonksiyonları üzerine etkisi oldukça düşüktür ${ }^{[13]}$.
Bu çalışmada, hipotezimiz; koroner cerrahisi geçirecek metabolik sendromlu hastalarda karaciğer eliminasyonundan bağımsız bir anestezik ilaç seçiminin, postoperatif karaciğer fonksiyonları üzerine olumlu etkisinin olabileceğidir. Bu amaçla açık koroner baypas cerrahisi geçirecek MS'li hastalarda, midazolam bazlı total intravenöz anestezi (TIVA) ve sevofluran bazlı inhalasyon anestezi uygulamasının, karaciğer fonksiyonları ve postoperatif komplikasyonlar üzerine etkilerini araştırdık.

\section{GEREÇ ve YÖNTEM}

Hastanemiz etik kurul onayı (No: E-17-1692, 03.01.2018) ve hasta onamlarının alınmasının ardından, prospektif gözlemsel çalışmamıza elektif açık koroner baypas cerrahisi planlanan erişkin hastalar dâhil edilmiştir. Ulusal kolesterol eğitim planı erişkin tedavi protokolü 3 (National Cholesterol Education Program Adult Treatment Panel III (ATP III))'e göre metabolik sendrom tanı kriterlerini karşılayan hastalar çalışma grubumuzu oluşturmuştur. Metabolik sendrom kriterleri:

- Abdominal obezite (VKi $\geq 30 \mathrm{~kg} / \mathrm{m}^{2}$ ya da bel çevresi kadınlarda $\geq 80 \mathrm{~cm}$, erkeklerde $\geq 94 \mathrm{~cm}$ )

- Trigliserid $\geq 150 \mathrm{mg} / \mathrm{dl}^{-1}$

- HDL seviyesi erkeklerde $<40 \mathrm{mg} / \mathrm{dl}^{-1}$, kadınlarda $<50 \mathrm{mg} / \mathrm{dl}^{-1}$

- Kan basınc $\geq 130 / 85$ mmHg ya da hipertansiyon

- Açlık kan glukozu $\geq 100 \mathrm{mg} / \mathrm{dl}^{-1}$ ya da tip 2 diabetes mellitus

* VKi (vücut kitle indeksi), HDL (yüksek yoğunluklu lipoprotein)

Dışlanma kriterleri olarak 18 yaş altı hastalar, acil veya redo cerrahiler, ejeksiyon fraksiyonu $\% 40$ 'ın altında olması, renal, hepatik, hematolojik hastalık varlığı, alkolizm, ilaç allerjisi olarak belirlenmiştir.

Diazepam $0.15 \mathrm{mg} / \mathrm{kg}$ ile bir gece önce premedike edilen hastalar ameliyat odasına geldikten sonra rutin kalp cerrahisi hazırlığı ve monitörizasyonu yapıldı. Alnına 1 bispektral indeks (BiS ${ }^{\mathrm{TM}}$, Covidien, MN, $A B D$ ) sensörlü yerleştirildi. Hastalar kapalı zarf yönte- 
mi ile gruplara ayrıldı. Grup TiVA, total intravenöz anestezi idamesi uygulanan hastalardan oluştu ( $n=38)$; Grup SEVO, sevofluran ile anestezi idamesi uygulanan hastalardan oluştu ( $n=38)$. Preoksijenasyon sonrası $10 \mu \mathrm{g} \mathrm{kg}^{-1}$ fentanil, $0.15 \mathrm{mg} / \mathrm{kg}^{-1}$ midazolam ile indüksiyon yapıldı. Bí 40-50 arasında stabil olduğunda, trakeal entübasyonu kolaylaştırmak için $0.8 \mathrm{mg} / \mathrm{kg}^{-1}$ roküronyum kullanıldı. Entübasyondan sonra, akciğerler volüm kontrollü modda $7-8 \mathrm{ml} / \mathrm{kg}^{-1}$ (ideal vücut ağırlığı) tidal hacimde, $\mathrm{O}_{2} /$ hava $\left(\mathrm{FiO}_{2}\right.$ 0.5) ve $5 \mathrm{~cm} \mathrm{H}_{2} \mathrm{O}$ PEEP karışımı ile ventile edildi. Solunum hızı, soluk sonu $\mathrm{CO}_{2}$ basıncını $35-45 \mathrm{mmHg}$ arasında tutacak şekilde ayarlandı. Arteriyel oksijen basıncı 100 ilâ 200 mmHg'de optimize edildi. Grup TiVA'nın anestezi idamesi sırasında Bis'i 40-60 arasında tutmak için yaklaşık $45 \mathrm{dk}$.'da 1 ameliyat boyunca $3 \mu \mathrm{g} / \mathrm{kg}^{-1}$ fentanil, 0.01-0.05 mg/ $/ \mathrm{kg}^{-1}$ midazolam ve $0.2 \mathrm{mg} / \mathrm{kg}^{-1}$ roküronyum bromür uygulandı. Grup SEVO anestezi idamesi sırasında BiS'i 40-60 arasında tutmak için ameliyat boyunca sevofluran 1-2 MAK, $3 \mu \mathrm{g} / \mathrm{kg}^{-1}$ fentanil ve $0.2 \mathrm{mg} / \mathrm{kg}^{-1}$ roküronyum bromür uygulandı. Kardiyopulmoner baypas sırasında, pompa için tasarlanmış sevofluran vaporizatörü kullanıldı. KPB sırasında sistolik kan basıncı 60-80 $\mathrm{mmHg}$, non-KPB dönemde tansiyon arteriyel $<140 / 80 \mathrm{mmHg}$ idame edildi. Gereğinde nitrogliserin $(0.2-0.8 \mathrm{mcg} / \mathrm{kg}-\mathrm{sa})$ infüzyonu başlandı. Orofaringeal sıcaklık takip edildi. Kardiyopulmoner baypas (KPB) sırasında kan gazı yönetimi için alfa-stat stratejisi kullanıldı. Hemoglobin konsantrasyonları KPB sırasında $7,5 \mathrm{~g} / \mathrm{dl}^{-1}{ }^{\prime}$ in üzerinde ve KPB'den sonra $8,5 \mathrm{~g} / \mathrm{dl}^{-1}{ }^{-1}$ in üzerinde tutuldu. Cerrahi işlem tamamlandığında anestezik uygulaması aynı anda durduruldu. Ekstübasyon ancak hastalar bilinçli yanıt verdikten ve yoğun bakım ünitesinde sözlü komutla derin nefes aldıktan sonra yapıldı.

Cerrahi yönetimde, sol internal mamarial arter çıkarıldıktan sonra heparinizasyon yapıldı, venöz ve aortik kanüller yerleştirildi. Kardiyopulmoner baypas, $36^{\circ} \mathrm{C}^{\prime}$ de 2.2-2.4 L/dak ${ }^{-1} \mathrm{~m}^{2}$ debi ile Nipro ${ }^{\circledR}$ oksijenatör kullanılarak başlatıldı (The Affinity NT Integrated Trillium CVR/Membran Oksijenatör, Medtronic, Minneapolis, MN). Prime volüm bileşimi, ringer laktat ve diğer katkı maddelerinden oluştu. KPB, orta derecede hipotermi $30-32^{\circ} \mathrm{C}^{\prime}$ de yapıldı. Anterograd kristaloid kardiyopleji (Plegisol ${ }^{\circledR}$ ) ile kardiyak arrest yapıldıktan sonra, $20 \mathrm{dk}$. arayla retrograd 1:4 oranında karışık kan kardiyoplejisi ile devam edildi. Distal anastomoz sonrası terminal sıcak kan kardiyoplejisi uygulanarak kros klemp açıldı ve ardından side klemp konarak proksimal anastomozlar yapıldı. Dekanülasyon sonrası otolog donasyon amacıyla ayrılan kan retransfüze edildi. Protamin ile heparin etkisi tersine çevrildi ve kardiyopulmoner baypas sonlandırıldı ve kanama kontrolü sonrası sternum kapatıldı.

Demografik ve klinik veriler, intraoperatif veriler, postoperatif komplikasyonlar, mortalite, ekstübasyon süresi ve yoğun bakımda kalış süresi ve taburculuk süresi kaydedildi. Hastaların preoperatif ve postoperatif 24. saat karaciğer enzimleri kaydedildi.

\section{İstatistiksel analiz}

Tüm istatistiksel analizler IBM SPSS 22.0 for Windows programı ile yapıldı. Verilerin temel özelliklerini tanımlamak için tanımlayıcı istatistikler hesaplandı. Kategorik değişkenlere göre TIVA ve SEVO gruplarını karşılaştırmak için Pearson ki-kare veya Fisher'ın kesin testi kullanıldı. Ek olarak, TiVA ve SEVO grupları sürekli veriler için Mann-Whitney $U$ testi veya 2 örnek t-testi ile karşılaştırıldı. Her 2 grup için ön ve son değerler arasındaki farkı değerlendirmek için Wilcoxon işaretli sıra testi kullanıldı. İki taraflı testlerden $<.05 \mathrm{p}$ değeri istatistiksel olarak anlamlı kabul edildi.

\section{BULGULAR}

Toplamda 76 hastanın dâhil edildiği çalışmada, her 2 grup yaş açısından karşılaştıııldığında, TiVA $(n=38)$ grubunda ortalama yaş 59.13 \pm 9.63 (39-79), SEVO $(n=38)$ grubunda ortalama yaş $60.34 \pm 6.89(44-73)$ yıl idi $(p>0.05)$. Euroscore değerleri benzerdi. TiVA ve SEVO grupları için cinsiyet ve komorbidite oranları Tablo 1'de sunulmuştur. Gruplar kan ürünü transfüzyonu, postoperatif komplikasyon ve 30 günlük mortalite oranları açısından karşılaştırıldı. Her 2 grup 


\begin{tabular}{|c|c|c|c|c|}
\hline \multirow[b]{2}{*}{ Değişkenler } & \multicolumn{2}{|c|}{ Grup n (\%) } & \multirow[b]{2}{*}{ Toplam } & \multirow[b]{2}{*}{ p-değeri } \\
\hline & TivA & SEVO & & \\
\hline Cinsiyet (n) & & & & 0.791 \\
\hline $\mathrm{K}$ & $10(52.6)$ & $9(47.4)$ & $19(100.0)$ & \\
\hline$E$ & $28(49.1)$ & $29(50.9)$ & $57(100.0)$ & \\
\hline Hipertansiyon (n) & $30(46.2)$ & $35(53.8)$ & $65(100.0)$ & 0.103 \\
\hline Hiperlipidemi (n) & $25(46.3)$ & $29(53.7)$ & $54(100.0)$ & 0.312 \\
\hline İnsülin direnci/Diyabet (n) & $36(53.7)$ & $31(46.3)$ & $67(100.0)$ & 0.153 \\
\hline $\mathrm{VKi} \geq 30 \mathrm{~kg} / \mathrm{m}^{2}(\mathrm{n})$ & $13(46.4)$ & $15(53.6)$ & $28(100.0)$ & 0.812 \\
\hline Bel çevresi (n) & $17(47.2)$ & $19(52.8)$ & $36(100.0)$ & 0.819 \\
\hline Kadın $\geq 80 \mathrm{~cm}$, Erkek $\geq 94 \mathrm{~cm}$ & & & & \\
\hline
\end{tabular}

*VKi: Vücut kitle indeksi

Tablo 2. TiVA ve SEVO gruplarının postoperatif komplikasyon gelişimi oranlarına göre karşılaştırması.

\begin{tabular}{lcccc} 
& \multicolumn{2}{c}{ Grup $\mathbf{n ~ ( \% ) ~}$} & & \\
\cline { 2 - 3 } Değişkenler & TiVA & SEVo & Toplam & p-değeri \\
\hline İntraoperatif Kan Ürünü (ü) & $10(40.0)$ & $15(60.0)$ & $25(100.0)$ & 0.222 \\
Postoperatif komplikasyon (n) & $5(45.5)$ & $6(54.5)$ & $11(100.0)$ & 0.744 \\
Postop AF & $3(60.0)$ & $2(40.0)$ & $5(100.0)$ & 1.000 \\
Postop pnömoni & $0(0.0)$ & $2(100.0)$ & $3(100.0)$ & 1.000 \\
Postop SVO & $2(66.6)$ & $1(33.3)$ & $23(100.0)$ & 0.493 \\
Postop kan ürünü (ü) & $11(47.8)$ & $12(52.2)$ & $1(100.0)$ & 0.803 \\
30 günlük mortalite & $0(0.0)$ & $1(100.0)$ & 1.000 \\
\hline
\end{tabular}

*VKi: Vücut kitle indeksi

arasında istatistiksel olarak anlamlı bir fark yoktu ( $p>0.05$ ) (Tablo 2).

Tablo 3'te kardiyopulmoner baypas süresi, ameliyat süresi, karaciğer enzim düzeyleri gibi intraoperatif ve postoperatif özelliklerin bir özeti sunulmaktadır. Yalnızca TIVA ve SEVO grupları arasında extübasyon süresi bakımından istatistiksel olarak anlamlı bir farklılık saptandı ( $p<0.05)$. Ancak, yoğun bakım ve hastane kalış süreleri gruplar arasında farklı değildi ( $p>0.05$ ). Preoperatif ve postoperatif HDL, LDL, TG, glukoz, ALT, AST, LDH, postoperatif drenaj, intravenöz mayi kullanımı gruplar arasında benzerdi (Tablo 3).

Preoperatif ve postoperatif laboratuvar parametrelerine göre TIVA ve SEVO gruplarının karşılaştırıldığı Tablo 4'te her 2 grupta da ALT, AST, LDH ve glukozun postoperatif değerleri, preoperatif değerlere göre istatistiksel olarak anlamlı yüksek bulundu $(p<0.05)$.

\section{TARTIŞMA}

Metabolik sendromlu hastaların açık koroner cerrahisinde karaciğer fonksiyonlarını etkileyen faktörlerden biri de kullanılan anestezi ilaçları olabilir. Bu çalışmada, izole KABG uygulanan metabolik sendromlu hastalarda midazolam bazlı TiVA ve sevofluran bazlı inhalasyon anestezi idamesinin postoperatif karaciğer fonksiyonları üzerine etkileri karşılaştırıldı ve her 2 grupta da ALT, AST, LDH ve glukoz değerlerinin ameliyat sonrası arttığı, ancak 2 grup arasında farklılık saptanmadığı görüldü. Bildiğimiz kadarıyla bu, metabolik sendrom olan hastalarda farklı anestezi türlerinin organ sistemleri üzerine etkisinin spesifik 
Tablo 3. TiVA ve SEVO grupları arasında hasta özelliklerinin karşılaştırması.

\begin{tabular}{|c|c|c|c|c|c|}
\hline & $\begin{array}{c}\text { TiVA } \\
\text { ortalama } \pm S D\end{array}$ & min.-mak. & $\begin{array}{c}\text { SEVO } \\
\text { ortalama } \pm S D\end{array}$ & min.-mak. & p-değeri \\
\hline $\mathrm{HDL}\left(\mathrm{mg} / \mathrm{dl}^{-1}\right)$ & $35.19 \pm 8.83$ & $21-57$ & $39.27 \pm 11.49$ & $24-67$ & $0.185^{+}$ \\
\hline $\mathrm{LDL}\left(\mathrm{mg} / \mathrm{dl}^{-1}\right)$ & $111.43 \pm 54.24$ & $18-252$ & $105.92 \pm 37.80$ & $33-194$ & $0.614^{¥}$ \\
\hline TG & $239.14 \pm 147.33$ & $73-758$ & $227.59 \pm 157.75$ & $68-865$ & $0.650^{+}$ \\
\hline Preop glukoz $\left(\mathrm{mg} / \mathrm{dl}^{-1}\right)$ & $132.47 \pm 34.05$ & $71-194$ & $126.37 \pm 38.37$ & $71-196$ & $0.394^{+}$ \\
\hline Preop ALT (mg/dl-1) & $23.87 \pm 11.79$ & $8-57$ & $20.70 \pm 11.64$ & $10-77$ & $0.146^{+}$ \\
\hline Preop AST $\left(\mathrm{mg} / \mathrm{dl}^{-1}\right)$ & $22.32 \pm 11.75$ & $9-57$ & $17.89 \pm 7.06$ & $11-46$ & $0.052^{+}$ \\
\hline Preop LDH $\left(\mathrm{mg} / \mathrm{dl}^{-1}\right)$ & $230.50 \pm 122.87$ & $155-906$ & $205.45 \pm 53.25$ & $129-384$ & $0.331^{+}$ \\
\hline Postop glukoz $\left(\mathrm{mg} / \mathrm{dl}^{-1}\right)$ & $177.16 \pm 47.26$ & $110-304$ & $159.32 \pm 41.35$ & $96-251$ & $0.117^{+}$ \\
\hline Postop ALT $\left(\mathrm{mg} / \mathrm{dl}^{-1}\right)$ & $26.89 \pm 12.25$ & $10-59$ & $29.53 \pm 13.70$ & $11-64$ & $0.371^{+}$ \\
\hline Postop AST (mg/dl $\left.{ }^{-1}\right)$ & $62.08 \pm 42.34$ & $27-258$ & $62.24 \pm 39.08$ & $22-227$ & $0.992^{+}$ \\
\hline Postop LDH (mg/dl $\left.{ }^{-1}\right)$ & $393.71 \pm 124.28$ & $245-844$ & $420.29 \pm 149.47$ & $244-870$ & $0.055^{+}$ \\
\hline Krosklemp süresi (dk) & $59.11 \pm 23.87$ & $18-108$ & $60.92 \pm 27.35$ & 23-131 & $0.170^{¥}$ \\
\hline Pompa süresi (dk) & $90.42 \pm 26.90$ & $32-132$ & $101.61 \pm 34.50$ & $46-147$ & $0.199^{¥}$ \\
\hline Ameliyat süresi (dk) & $273.42 \pm 61.32$ & $110-405$ & $2866.74 \pm 91.62$ & $104-460$ & $0.212^{¥}$ \\
\hline Peroperatif sIVI (ml) & $1352.63 \pm 324.44$ & $700-2000$ & $1539.47 \pm 481.85$ & $800-2600$ & $0.095^{+}$ \\
\hline Pompa sIVI (ml) & $1534.21 \pm 415.27$ & $1100-2800$ & $1435.00 \pm 522.07$ & $1100-4000$ & $0.067^{+}$ \\
\hline İdrar (ml) & $1259.21 \pm 500.39$ & $150-2000$ & $1151.32 \pm 529.21$ & $400-2200$ & $0.292^{+}$ \\
\hline Extübasyon süre (saat) & $9.41 \pm 3.96$ & $4-22$ & $7.16 \pm 1.81$ & 4-13 & $0.008^{*}$ \\
\hline Yoğun bakım yatış (gün) & $1.47 \pm 1.00$ & $1-6$ & $1.45 \pm 0.89$ & $1-5$ & $0.995^{+}$ \\
\hline Hastane yatış (gün) & $6.05 \pm 2.44$ & $3-16$ & $5.29 \pm 1.61$ & $0-8$ & $0.405^{+}$ \\
\hline Drenaj 24 saat (ml) & $633.42 \pm 137.20$ & $350-1000$ & $699.21 \pm 361.80$ & $150-2000$ & $0.521^{+}$ \\
\hline
\end{tabular}

*: $p<0.05$

*: Independent samples $t$ t-test

${ }^{+}$: Mann-Whitney $U$ test

ALT: Alanin aminotransferaz, AST: Asetil aminotransferaz, HDL: Yüksek yoğunluklu lipoprotein,

LDL: Düşük yoğunluklu lipoprotein, TG: Trigliserit, VKi: Vücut kitle indeksi

olarak karşılaştırıldığı ilk çalışma olabilir.

Kardiyak cerrahi, KPB'nin doğası ve ciddi şekilde etkilenen doku perfüzyonu nedeniyle global kardiyovasküler dinamiklerdeki önemli değişikliklerle ilişkilidir. Kalp cerrahisi sırasında karaciğer perfüzyonunun, azalmış kalp debisi, pulsatil olmayan kan akışı, inflamasyonun aktivasyonu ve hipotermi gibi nedenlerle bozulduğu bildirilmiştir ${ }^{[14]}$. Bununla beraber, perfüzyonun KPB'dan çok daha önce, anestezi indüksiyonu ile bozulmaya başladığını iddia eden yazarlar da vardır ${ }^{[15]}$. Literatürde MS hastalarına uygulanan anestezi yöntemlerinin organ sistemleri üzerindeki etkilerini değerlendiren bir çalışma saptanmadığı gibi, MS hastaları için en uygun anestezikler hakkında çok az veri vardır ${ }^{[8]}$. Bütün inhalasyon anesteziklerinin ortalama arter basıncı ve portal kan akımı üzerinde azaltıcı etkiye sahip olmasına rağmen, sevofluranın hepatik fonksiyonları daha iyi koruduğu iddia edilmektedir. Midazolamla ise KPB süresince ilaç klirensinde ve proteinlere bağlanmada azalma, yinelenen dozlar nedeniyle uzamış depresif etkiler belirtilmiştir [16]. Kronik karaciğer hastalığı olan hastaların karaciğer cerrahisi sonrası anestezik ilaçlara (midazolam ve sevofluran) bağlı hepatotoksik yan etkiler gözlenmiştir ${ }^{[17,18]}$. Diğer bir çalışmada ise, kronik karaciğer hastalığı olan hastalarda uygulanan anestezinin mortaliteyi etkilemediği saptanmıştır ${ }^{[19]}$. Çalışmamızda, her 2 grupta da preoperatif değerlere göre postoperatif 24 . saatte bakılan karaciğer enzimleri anlamlı derecede yüksek bulunsa da grupların birbirine üstünlüğü yoktu, ayrıca herhangi katastrofik karaciğer toksisite ile de karşılaşılmadı.

Vücut kitle indeksinin genellikle erken postoperatif komplikasyonları arttırdığı, ancak mortaliteyi etkilemediği bildirilmiştir ${ }^{[20,21]}$. Başka bir çalışmada, VKi'i mortalite ve postoperatif komplikasyonlarla ilişkilendirilememiştir ${ }^{[22]}$. Obez ve obez olmayan ergenlerde midazolamın farmakokinetiği incelenmiş, VKi'inin 
H. Yiğit Özay ve ark., Metabolik Sendromlu Koroner Baypas Hastalarında Uygulanan İki Farklı Anestezi Tipinin Postoperatif Karaciğer Fonksiyonları Üzerine Etkisi

Tablo 4. TiVA ve SEVO gruplarının preoperatif ve postoperatif değişkenler açısından karşılaştırması.

\begin{tabular}{|c|c|c|c|c|c|}
\hline & ortalama $\pm S D$ & min.-mak. & ortalama $\pm S D$ & min-mak & p-değeri \\
\hline TivA & Preoperatif Glukoz & & Postoperatif Glukoz & & \\
\hline SEVO & $\begin{array}{l}132.47 \pm 34.05 \\
126.37 \pm 38.37\end{array}$ & $\begin{array}{l}71-194 \\
71-196\end{array}$ & $\begin{array}{l}177.16 \pm 47.26 \\
159.32 \pm 41.35\end{array}$ & $\begin{array}{c}110-304 \\
96-251\end{array}$ & $\begin{array}{l}<.001^{*} \\
<.001^{*}\end{array}$ \\
\hline TiVA & Preoperatif ALT & & Postoperatif ALT & & \\
\hline SEVO & $\begin{array}{l}21.57 \pm 11.79 \\
20.70 \pm 11.64\end{array}$ & $\begin{array}{l}11-57 \\
10-77\end{array}$ & $\begin{array}{l}28.89 \pm 12.25 \\
29.53 \pm 13.70\end{array}$ & $\begin{array}{l}10-59 \\
11-64\end{array}$ & $\begin{array}{l}<.001^{*} \\
<.001^{*}\end{array}$ \\
\hline TIVA & Preoperatif AST & & Postoperatif AST & & \\
\hline SEVO & $\begin{array}{c}22.32 \pm 11.75 \\
17.89 \pm 7.06\end{array}$ & $\begin{array}{c}9-57 \\
11-46\end{array}$ & $\begin{array}{l}62.08 \pm 42.34 \\
62.24 \pm 39.08\end{array}$ & $\begin{array}{l}27-258 \\
22-227\end{array}$ & $\begin{array}{l}<.001^{*} \\
<.001^{*}\end{array}$ \\
\hline $\begin{array}{l}\text { TIVA } \\
\text { SEVO }\end{array}$ & $\begin{array}{c}\text { Preoperatif LDH } \\
230.50 \pm 122.87 \\
205.45 \pm 53.25\end{array}$ & $\begin{array}{l}155-906 \\
129-384\end{array}$ & $\begin{array}{c}\text { Postoperatif LDH } \\
393.71 \pm 124.28 \\
420.29 \pm 149.47\end{array}$ & $\begin{array}{l}245-844 \\
244-870\end{array}$ & $\begin{array}{l}<.001^{*} \\
<.001^{*}\end{array}$ \\
\hline
\end{tabular}

¥: Wilcoxon Signed Rank test

periferik dağılım hacmi ve midazolamın kompartmanlar arası dağılım klirensini arttırdığı gösterilmiştir [23]. Yine obez ve obez olmayan bireylerde midazolam klirensinde bir fark bulunmamasına rağmen ${ }^{[24]}$, bariatrik cerrahiden 1 yıl sonra hastalarda midazolam klirensinde 1.7 kat artış bildirilmiştir ${ }^{[25]}$. Çalışmamız$\mathrm{da}$, her 2 grup için toplamda $\% 28$ oranında $\mathrm{VKI} \geq 30$ $\mathrm{kg} / \mathrm{m}^{2}$ ve $\% 36$ oranında abdominal obezite vardı. Obezite açısından kullanılan 2 farklı anestezi yönteminin postoperatif komplikasyon ve mortalite üzerine etkisi saptanmadı. İnvitro insan karaciğerinde diyabetin azalmış CYP3A4 aktivitesi ile ilişkili olduğu belirtilmiştir ${ }^{[26]}$. Hastalarımızda toplamda \%67 oranında ya bozulmuş glukoz toleransı ya da diyabet mevcuttu. Her 2 grupta postoperatif glukoz seviyeleri artmasına rağmen, komplikasyon ve mortalite açısından fark yoktu. MS'ye eşlik eden komorbiditelerin (hipertansiyon, obezite, hiperglisemi, anormal lipit düzeyleri) ayrı ayrı incelenmesi ve olası $\mathrm{KAH}$ (koroner arter hastalığı), KKY (konjestif kalp yetmezliği), OSAS (obstruktif uyku apne sendromu) ve DVT (derin ven trombozu) için anestezi ile ilgili ön koşulların değerlendirilmesi önerilmektedir. Ancak, anestezik ilaç yönetimi hakkında öneriler sınırlıdır ${ }^{[8]}$. Çalışmamız$\mathrm{da}$, her ne kadar anlamlı sonuç bulmamış olsak da hasta sayımızın kısıtlı olması bunda etken olmuş olabilir. Yapılacak büyük çaplı çalışmalar ya da deneysel araştırmaların aydınlatıcı olacağı görüşündeyiz.
Metabolik sendromun KABG sonrası operatif mortalite üzerine etkisinin değerlendirildiği bir çalışmada, MS'in bağımsız ve güçlü bir gösterge olduğu belirtilmiştir ${ }^{[27]}$. Literatürde, MS için daha yüksek kardiyovasküler ve pulmoner komplikasyonlar bildirmiştir [7,8]. Öte yandan metabolik sendromu olan ve olmayan obez hastaların bariatrik cerrahisi sonrası, postoperatif komplikasyonlar acısından fark gösterilememiştir ${ }^{[28]}$. Çalışmamızdaki hasta grubumuzun tamamı metabolik sendromlu hastalardan oluşmaktaydı. Metabolik sendromu olmayan hastalarla bir karşılaştırma yapmadık. Bununla beraber, SEVO ve TIVA uyguladığımız metabolik sendromlu koroner baypas hastalarımızda postoperatif komplikasyonlar ve mortalite açısından anlamlı bir fark bulmadık. Çalışmamızda, postoperatif dönemde SEVO grubunda 1 hastada 30 günlük mortalite gözlendi, dolayısıyla metabolik sendromlu KABG hastalarımızda mortalite oranı \%1.31 olarak seyretti. Çalışmamızda, Echahidi ve ark.'nın ${ }^{[27]}$ çalışmasındaki orandan daha düşük bir mortalite gözlendi. Ayrıca postoperatif komplikasyon oranlarımız yine gruplar arasında farklılık göstermedi ve çalışma grubunda genel komplikasyon oranı \%14.47 olarak saptandı. Echahidi ve ark. ${ }^{[27]} \mathrm{MS}$ 'li KABG hastalarında, postoperatif yeni başlangıçlı AF oranının 2 kat arttığını söylemişlerdir (\%6, \%12). Çalışmamızda, postoperatif AF oranı \%6.57 olarak saptandı. 
Açık koroner cerrahi geçirecek metabolik sendromlu hastalarda karaciğer eliminasyonundan bağımsız bir anestezik ilaç seçiminin, postoperatif karaciğer fonksiyonları üzerine olumlu etkisinin olabileceği hipotezi ile yola çıktığımızda, karaciğer fonksiyonları üzerine etkili olabilecek diğer faktörleri standardize etmek zordu. Karaciğer enzimleri için postoperatif dönemde tek ölçüm yerine ilerleyen günlerde birkaç ölçüm yapmak daha aydınlatıcı olabilirdi. Ayrıca hasta sayısının az olması kısıtlayıcı diğer bir faktördü.

Sonuç olarak, çalışmamızda, metabolik sendromlu koroner baypas hastalarında midazolam bazlı TiVA ve sevofluran bazlı inhalasyon anestezi uygulamalarının karaciğer fonksiyonları açısından birbirine üstünlüğü olmadığını saptadık. Daha fazla sayıda hasta ile detaylı parametrelerin araştırıldığı çalışmalar bu konu için yol gösterici olacaktır.

\section{KAYNAKLAR}

1. Wang L, Qian X, Wang M, Tang X. Which factor is the most effective one in metabolic Sydrome on the outcomes after coronary artery bypass graft surgery? A cohort study of 5 Years. Journal of Cardiothoracic Surgery 2018;13:1. https://doi.org/10.1186/s13019-017-0682-5

2. Samson SL, Garber AJ. Metabolic syndrome.Endocrinol Metab Clin North Am. 2014 Mar;43(1):1-23. https://doi.org/10.1016/j.ecl.2013.09.009

3. Eckel RH, Grundy SM, Zimmet PZ. The metabolic syndrome.Lancet 2005 Apr 16-22;365(9468):1415-28. https://doi.org/10.1016/S0140-6736(05)66378-7

4. Younossi ZM, Koenig AB, Abdelatif D, Fazel Y, Henry L, Wymer M. Global epidemiology of nonalcoholic fatty liver disease-meta-analytic assessment of prevalence, incidence and outcomes. Hepatology. 2016;64:73-84. https://doi.org/10.1002/hep.28431

5. Hobeika C, Ronot M, Beaufrere A, Paradis V, Soubrane $\mathrm{O}$, Cauchy F. Metabolic syndrome and hepatic surgery. Journal of Visceral Surgery 2020;157:231-8. https://doi.org/10.1016/j.jviscsurg.2019.11.004

6. Grundy SM. Metabolic syndrome pandemic. Arterioscler Thromb Vasc Biol. 2008;28:629-36. https://doi.org/10.1161/ATVBAHA.107.151092

7. Tzimas P, Petrou A, Laou E, Milionis H, Mikhailidis DP, Papadopoulos G. Impact of metabolic syndrome in surgical patients:should we bother? British Journal of Anaesthesia 2015;115(2):194-202. https://doi.org/10.1093/bja/aev199

8. Tung A. Anaesthetic considerations with the metabolic syndrome. British Journal of Anaesthesia 2010;105(S1):i24-i33. https://doi.org/10.1093/bja/aeq293

9. Isomaa B. A major health hazard: the metabolic syndrome. Life Sci 2003;73:2395-411. https://doi.org/10.1016/S0024-3205(03)00646-5

10. Wandel C, Bocker R, Bohrer H, Browne A, Rugheimer E, Martin E. Midazolam is metabolized by at least three different cytochrome P450 enzymes. British Journal of Anaesthesia 1994;73:658-61. https://doi.org/10.1093/bja/73.5.658

11. LiverTox: Clinical and Research Information on DrugInduced Liver Injury [Internet]. Bethesda (MD): National Institute of Diabetes and Digestive and Kidney Diseases; 2012. Midazolam. [Updated 2017 Jan 24]. https://www.ncbi.nlm.nih.gov/books/

12. Mayte B, Julio L, Jose GA, et al. Myocardial oxidative stress protection by sevoflurane vs. propofol: a randomised controlled study in patients undergoing off-pump coronary artery bypass graft surgery. European Journal of Anaesthesiology: December 2011Volume 28- Issue 12- p 874-881. https://doi.org/10.1097/EJA.0b013e32834bea2a

13. Lorsomradee $S$, Cromheecke S, Lorsomradee $S$, Hert SG. Effects of Sevoflurane on Biomechanical Markers of Hepatic and Renal Dysfunction After Coronary Artery Surgery. Journal of Cardiothoracic and Vascular Anesthesia Volume 20, Issue 5, October 2006, Pages 684-690. https://doi.org/10.1053/j.jvca.2006.02.035

14. Sabzi F, Faraji R. Liver function tests following open cardiac surgery. J Cardiovasc Thorac Res. 2015;7(2):4954. https://doi.org/10.15171/jcvtr.2015.11

15. Maier S, Hasibeder WR, Hengl C, et al. Effects of phenylephrine on the sublingual microcirculation during cardiopulmonary bypass. Br J Anaesth. 2009; 102:485-91. https://doi.org/10.1093/bja/aep018

16. Dalal A, Lang JD. Anesthetic considerations for patients with liver disease. Submitted: March 13th 2012Reviewed: October 9th 2012Published: February 13th 2013. https://doi.org/10.5772/54222

17. Safari S, Motavaf M, Siamdoust SAS, Alavian SM. Hepatotoxicity of halogenated inhalational anesthetics. Iran Red Crescent Med J. 2014 Sep16(9):e20153. Published online 2014 Sep 5. https://doi.org/10.5812/ircmj.20153

18. Gronbaek L, Watson H, Vilstrup H, Jepsen P. Benzodiazepines and risk for hepatic encephalopathy in patients with cirrhosis and ascites.United European Gastroenterol J. 2018 Apr6(3):407-12. Published online 2017 Aug 23. https://doi.org/10.1177/2050640617727179

19. Ziser A, Plevak DJ, Wiesner RH, Rakela J, Offord KP, Brown DL. Morbidity and mortality in cirrhotic patients undergoing anesthesia and surgery. Anesthesiology. 1999;90:42-53. https://doi.org/10.1097/00000542-199901000-00008

20. Yap CH, Mohajeri M, Yii M. Obesity and early complications after cardiac surgery. Med J Aust. 2007; 186:350-4. https://doi.org/10.5694/j.1326-5377.2007.tb00935.x

21. Demir A, Aydinli B, Güçlü ÇY, et al. Obesity and postoperative early complications in open heart surgery. J Anesth. 2012;26:702-10. https://doi.org/10.1007/s00540-012-1393-7 
22. Balcı E, Aykut A, Demir A, Sabuncu Ü, Koçulu R, Karadeniz Ü. In-hospital mortality and complications following coronary artery bypass surgery; is it possible to predict with preoperative values? JARSS 2019;27(1):56-62

https://doi.org/10.5222/jarss.2019.32042

23. Gade C, Sverrisdottir E, Dalhoff K, et al. Midazolam Pharmacokinetics in Obese and Non-obese Children and Adolescents. Clin Pharmacokinet 2020;59:643-54. https://doi.org/10.1007/s40262-019-00838-1

24. Brill MJ, van Rongen A, Houwink AP, Burggraaf J, van Ramshorst B, Wiezer RJ, et al. Midazolam pharmacokinetics in morbidly obese patients following semi-simultaneous oral and intravenous administration: a comparison with healthy volunteers. Clin Pharmacokinet. 2014;53(12):931-41. https://doi.org/10.1007/s40262-014-0166-x

25. van Rongen A, Brill MJE, Vaughns JD, et al. Higher Midazolam clearance in obese adolescents compared with morbidly obese adults. Clin Pharmacokinet
2018;57:601-11.

https://doi.org/10.1007/s40262-017-0579-4

26. Jamwal R, de la Monte SM, Ogasawara K, Adusumalli S, Barlock BB, Akhlaghi F. Nonalcoholic fatty liver Disease and Diabetes Are Associated with Decreased CYP3A4 Protein Expression and Activity in Human Liver. Molecular Pharmaceutics, 2018;15(7):2621-32.

https://doi.org/10.1021/acs.molpharmaceut.8b00159

27. Echahidi N, Mohty D, Pibarot P, et al. Obesity and metabolic syndrome are independent risk factors for atrial fibrillation after coronary artery bypass graft surgery. Circulation 2007;116: 1213-9. https://doi.org/10.1161/CIRCULATIONAHA.106.681304

28. Purnell JQ, Selzer F, Smith MD, et al. Metabolic syndrome prevalence and associations in a bariatric surgery cohort from the Longitudinal Assessment of Bariatric Surgery-2 study. Metab Syndr Relat Disord 2014;12:86-94.

https://doi.org/10.1089/met.2013.0116 